\title{
UM OLHAR SOBRE O PROCESSO DE PAZ ISRAEL- PALESTINA E A PROBlemática dA TERRA No doCumentário Promises (2001)
}

\author{
Claudinei Lodos
}

\begin{abstract}
Resumo
O processo de paz entre israelenses e palestinos, ocorrido na década de 1990, está representado no documentário estadunidense Promises (2001). A questão da posse da terra apresenta destaque no filme através das vozes de crianças árabes e judias que debatem sobre os seus direitos de pertencimento. Neste artigo, demonstramos a representação do conflito pelo documentário, destacando a problemática da terra e considerando a contextualização histórica do período em que o documentário foi produzido.
\end{abstract}

\section{A LOOK AT The ISRAeli-PALestinian PEACE PROCESS AND THE LAND ISSUE IN THE DOCUMENTARY PROMises (2001)}

\begin{abstract}
The peace process between Israelis and Palestinians, which occurred in the 1990's, is depicted in the American documentary Promises (2001). The issue of land appropriation is highlighted in the film through both Arabian and Jewish children's voices while debating about their rights of belonging. In this article, we demonstrate the representation of the conflict through the documentary, highlighting the land problem, and considering the historical contextualization of the period in which the documentary was produced.
\end{abstract}

KEYWORDS

Palestine; documentary; Israel; conflict

\section{INTRODUÇÃO}

O documentário estadunidense Promises, lançado em 2001, apresenta como pano de fundo o contexto histórico em que ocorreu o processo de paz entre os povos israelenses e palestinos. O propósito deste artigo é demonstrar como a questão da posse da terra, que permeia o conflito na região, desde 1948, é debatida neste documentário durante o período em que o processo de paz vigorou. O documentário direciona o debate das questões irreconciliáveis a partir das vozes de crianças, árabes e judias, que apresentam discursos pelo viés da religiosidade. 
Promises foi rodado no Oriente Médio e produzido nos Estados Unidos, sendo assim, procuramos questionar as implicações decorrentes do lugar de produção para compreender como o documentário articulou a opinião sobre o conflito entre palestinos e israelenses. O filme apresenta um histórico da questão Palestina e procura colocar em debate, a partir das entrevistas e depoimentos, as questões mais candentes sobre o conflito. O documentário não é uma síntese do conflito, porém o seu espectador pode constatar as tensões que fazem parte desta sociedade, a partir de sua voz, que se refere à construção tanto da imagem quanto da narrativa fílmica.

\section{O documentário Promises}

Promises foi produzido em parceria com a Independent Television Service (ITVS)', importante emissora norte-americana. A produção começou em 1995 e foi até ao ano 2001, quando o documentário foi lançado no Festival Internacional de Roterdão. Promises foi dirigido por Justine Shapiro, apresentadora da série de viagens Globe Trekker, neste período; B.Z. Goldberg ${ }^{2}$, judeu-americano e jornalista durante a primeira intifada ${ }^{3}$ (1987-1993), e Carlos Bolado, cineasta mexicano. No documentário, Goldberg diz ser judeu, mas não praticante do judaísmo. Também protagonista da trama, ele mostra a sua identidade judaico-americana e afirma ser fluente na língua hebraica e árabe, porque estudou em Israel quando criança.

O documentário afirma que as crianças da Palestina tinham algo a dizer sobre a intifada e o processo de paz. É nesta perspectiva, que Goldberg e a equipe de produção selecionam sete crianças moradoras de Jerusalém e arredores - entre elas: árabes palestinos e judeus israelenses - para participarem da produção deste documentário. Yarko e Daniel, de Jerusalém Ocidental (setor israelense); Mahmoud, de Jerusalém Oriental (setor palestino); Shlomo, da Cidade Antiga (bairro judeu); Sanabel, de Zakarieh, porém, moradora de um Campo de Refugiados em Deheishe (Cisjordânia); Moishe, de Beit-El, um assentamento judeu e Faraj, também de Deheishe.

Esta produção cinematográfica apresenta, por meio de depoimentos e entrevistas, o discurso de crianças que habitam na Palestina. A problemática do conflito está explicitada na produção deste documentário, cuja observação é possível aquilatar as questões concernentes ao conflito que se mantêm candentes devido à perpetuação e irreconciliação do mesmo. Em síntese, são elas: a questão da terra e a quem é dado o direito de posse; vida religiosa dos povos, árabes e judeus; segurança de ambos os povos que transitam na Palestina; questão das fronteiras e o seu alargamento; força do

\footnotetext{
' Na década de 1990, de acordo com Roger Parry, a ITVS foi uma das grandes emissoras, ao lado da BBC, American Broadcasting Company (ABC), Columbia Broadcasting System (CBS) e NBC, que definiram a indústria (Parry, 2012, p. 279).

${ }^{2}$ B.Z. Goldberg também participou de organizações pacifistas, tais como: Israeli army, the Toyota group (Japão) AT\&T, MIT, Columbia University, The Interfaith Committee on the Middle East e Solidarity (Polónia). No período da primeira intifada, retornou para Jerusalém para noticiar o evento para os telejornais da Reuters TV, the BBC, NBC, CNN e NHK (Japanese TV). Retirado de http://www.promisesproject.org/credits.html

${ }_{3}^{3}$ Em dezembro de 1987 irrompeu o primeiro levante popular palestino, em decorrência da opressão e ocupação israelense. Este levante ficou conhecido como a primeira intifada e foi até 1993 (Pappé, 2008, p. 274).
} 
exército israelense e a resistência palestina. Todas estas questões são discutidas através das narrativas dessas crianças que "atuam" a sua própria história.

No tocante à etnicidade 4 , o histórico do conflito israelo-palestino demarca as diferenças étnicas que foram estabelecidas entre ambos os povos ao longo do processo, a partir das identidades construídas nas relações entre o "Eu" e o Outro, como aquele se opõe. Poutignat e Streiff-Fernart (1998, p. 123) afirmam que os pesquisadores compartilham da ideia de que "a pertença a um grupo implica a existência de uma categoria de excluídos". Neste viés, consideramos que a identidade israelense - a partir da fundação do Estado de Israel - e a consciência de uma identidade árabe-palestina, que floresceu na luta contra a ocupação sionista, configuram um cenário de disputa explicitado pela questão da etnicidade. Os autores ainda salientam que a etnicidade "ao mesmo tempo que afirma um Eu coletivo, nega um Outro coletivo. Sua característica principal é a emergência de uma consciência de separação e de formas de interação que só podem surgir num contexto social comum" (Poutignat \& Streiff-Fenart, 1998, p. 124).

O documentário Promises trata das fronteiras construídas nesta sociedade, além de propor - através do processo de produção - o diálogo entre ambos os povos. O processo de paz, vigente no período de produção do filme, representou um enfraquecimento da luta do povo palestino, que na década de 1980 se fortaleceu e conquistou notoriedade dentro e fora da região do conflito. As promessas contidas no documentário em análise tratam das tentativas frustradas de setores da sociedade israelense-palestina em firmar um acordo e acabar com o conflito. Promises sensibiliza o espectador para que ele adentre as questões candentes do conflito, mas não deixa de ser mais uma voz frustrada em meio a tantas outras que ecoam pelo fim desta guerra.

É válido salientar que este documentário é uma representação da questão palestina numa perspectiva ocidental. Isto implica a compreensão e construção de uma análise crítica pertinente à origem da voz deste documentário. Nichols esclarece a especificidade do documentário relativo às diferentes questões de sua produção e aponta para a concepção da voz como importante elemento que orienta e organiza o filme: "o fato de os documentários não serem uma reprodução da realidade dá a eles uma voz própria. Eles são uma representação do mundo, e essa representação significa uma visão singular do mundo" (Nichols, 2005, p. 73).

Existe no documento fílmico uma relação implícita com o espectador, que mostra o poder que o filme tem ao proporcionar a sensação de que se testemunha eventos. Burke considera que "esta sensação de testemunha é ilusória" e que "o diretor está preocupado não somente com o que aconteceu realmente, mas também em contar uma história que tenha forma artística e que possa mobilizar os sentidos de muitos espectadores" (Burke, 2004, p. 200).

Promises retrata o conflito israelo-palestino desde a guerra de 1948. Para a compreensão da narrativa fílmica, observamos que o modo participativo - categoria utilizada

\footnotetext{
${ }_{4}^{4}$ Poutignat e Streiff-Fernart compreendem que a questão da etnicidade possibilita "teorizações diversas" (1998, p. 120). Todavia, os autores salientam que o estudo da etnicidade consiste "em inventariar o repertório das identidades disponíveis em uma situação pluriétnica dada e descrever o campo de saliência dessas identidades nas diversas situações de contato" (Poutignat \& Streiff-Fernart, 1998, p. 117).
} 
por Nichols para especificar um subgênero do documentário -, faz parte da produção de Promises. Segundo o autor: "os documentaristas também vão ao campo; também eles vivem entre os outros e falam de sua experiência ou representam o que experimentaram" (Nichols, 2005, pp. 153-155).

No filme, Goldberg realiza entrevistas, aparece também mediando os diálogos entre as crianças árabes e judias, além de contar a sua experiência como um judeu que residiu nos arredores de Jerusalém e retornou como jornalista no período da primeira intifada. O documentário exibe uma rápida introdução, em que o diretor interage com as crianças selecionadas, mostra a cidade vista do alto, um mapa e imagens das ruas da Jerusalém Oriental e Ocidental. Após apresentar as crianças e os locais onde elas moram, o documentário centraliza o debate sobre o conflito a partir da problemática da terra e articula a produção fílmica reproduzindo no documentário o que estava em discussão no período, a saber, o processo de paz.

O espectador observa, logo na primeira cena, a sombra de algumas crianças brincando na escada horizontal de um parque, as vozes de meninos e meninas que se perdem ao som da tocante música Bayaty (Mansurov, 1993, faixa 3) e a palavra Promises, também em árabe e hebraico. Na sequência das imagens que apresentam a cidade de Jerusalém do alto, Goldberg, em voz over5, afirma: "eu acho que a minha infância aqui, em Jerusalém, foi normal, mas ser "normal" no Oriente Médio significa conviver com a guerra. Estouram conflitos, bombas explodem, pessoas morrem" (Goldberg citado em Promises, 2001).

A câmera registra pela cidade de Jerusalém, no setor israelense, as lojas de segmento fast food. Logo em seguida, no despertar do dia, o filme apresenta os irmãos, Yarko e Daniel, judeus seculares, e depois segue para o setor palestino, onde ocorre a primeira entrevista com Mahmoud, árabe-palestino e muçulmano. Os árabes e judeus, a cidade no seu aspecto ocidental e a música oriental são elementos que se entrecruzam, revelando a proximidade e as tensões que surgem a partir da convivência destes grupos étnicos. Goldberg, já na introdução, destaca a representação difundida do Oriente Médio como um lugar de conflitos, de forma a naturalizar a relação das pessoas com os problemas ali enfrentados e ainda não deixa de destacar que esta história diz respeito à sua infância. Ele narra sobre a problemática do conflito e menciona as negociações como se o observador tivesse conhecimento preliminar do processo de paz.

De Jerusalém, Goldberg segue para os territórios ocupados e passa facilmente por um posto de fiscalização israelense. Na movimentação constante do veículo, o sujeito da câmera filma no caminho percorrido: destroços, um carro abandonado, a estreita estrada e algumas belas edificações (casas, pequenos prédios e uma igreja). Goldberg discorre sobre a guerra de 1948 e seus significados tanto para o povo israelense quanto para os palestinos.

Como resultado da guerra [1948], 750 mil palestinos fugiram, ou foram expulsos da sua terra e tornaram-se refugiados. Campos de refugiados foram

\footnotetext{
5 Também conhecida como voz de Deus, a voz over é a locução fora de campo (Ramos, 2008, p. 23).
} 
abertos nos países árabes vizinhos. Em 1967, Israel tomou a Faixa de Gaza e a Cisjordânia. Os campos ficaram sob ocupação militar israelense. No campo de refugiados de Deheishe, moram mais de 11 mil palestinos. São os refugiados de 1948, mais seus filhos, netos e bisnetos. (Goldberg citado em Promises, 2001)

Em Deheishe, campo de refugiados localizado na Cisjordânia, Sanabel relata a expulsão da terra e a formação do campo. Esta aconteceu em princípio nas barracas e depois em pequenas edificações. Para tornar o discurso verossímil, o encadeamento das cenas é construído - após a apresentação de Sanabel - com uma gravação em preto e branco (filme de arquivo), a fotografia enquadrada do campo, também em preto e branco, e finaliza com o campo no tempo da produção do filme. O pai de Sanabel participou da Frente Popular de Libertação da Palestina (FPLP) como líder local e foi preso sem ser indiciado ou julgado. Esta organização foi integrada na OLP - Organização para a Libertação da Palestina, após o episódio de 1967, juntamente com a Fatah, liderada por Yasser Arafat, Frente Popular Democrática pela Libertação da Palestina, ramificação da FPLP, Saiqa, grupo da Síria, entre outras de menor expressão.

A OLP estava comprometida com as ideias que visavam a libertação dos palestinos, e por isso enfatizava o retorno dos palestinos exilados para os territórios ocupados por Israel. A princípio, o foco da organização era a libertação nacional ao invés de independência nacional. Esta posição se inverteu apenas com a Declaração de Independência Palestina, em 1988. Em parte, o primeiro alinhamento não abarcava os palestinos que moravam nos territórios ocupados, como a "Família da Terra", por exemplo, um grupo de palestinos remanescentes. Segundo Said, "sua ação era orientada pelo imperativo de permanecer na terra, fortalecendo a coesão da comunidade, acomodando-se ao sistema político israelense e, no entanto, lutando por direitos iguais". Entretanto, muitos palestinos reconheciam a OLP como a "única esperança política". Conforme Said, a OLP transformou o palestino, que outrora estava passivo, em um "ser politicamente participativo". Israel identificava a organização com o terrorismo e somente a reconheceu como representante do povo palestino na véspera do acordo de Oslo (Said, 2012, p. 154).

É ainda na alvorada que a família de Sanabel se dirige para a prisão Ashkelon, em Israel. A viagem que leva a família ao encontro do pai dura mais de quatro horas, além do longo tempo de espera. A visita é de apenas meia hora. Goldberg relata que fez um pedido para visitar o pai de Sanabel, mas foi negado porque os israelenses consideram que ele representa um "risco de segurança" e por isso somente a família poderia visitá-lo. Para Sanabel, os judeus se apropriaram das terras que pertenciam aos palestinos e prenderam o seu pai na prisão. Ela não concebe a paz neste momento da história. Goldberg destaca no filme que a FPLP, da qual o pai era líder local, não estava alinhada com o acordo de paz. Isto revela que a OLP, liderada por Yasser Arafat, não estava coesa nas diretrizes do acordo. Sanabel, a partir de uma percepção política do conflito e engajada na causa palestina - participou do grupo de dança tradicional que visava "contar a história dos refugiados", celebrando desta forma, a resistência palestina. Ela experienciou a dor da distância do pai, mas se fortaleceu na luta por um país palestino independente. 


\section{A QUESTÃo DA TERRA NO DOCUMENTÁRIO}

O slogan sionista criado no final do século XIX, "uma terra sem povo, para um povo sem terra" (Said, 2012, p. 11), apresenta uma problemática na qual as crianças do filme se inserem. O direito de pertença é debatido no filme pelos judeus - ortodoxos e seculares - e árabes palestinos. $O$ aspecto religioso está evidenciado nas palavras e práticas do menino de Jerusalém, Mahmoud, mas não aparece nas falas das crianças de Deheishe. É evidente que cada um deles, judeus e árabes, representa uma posição comprometida com o seu lugar de influência. No tocante a esta questão, o documentário abre o debate e permite que as crianças se expressem; para isto, o primeiro a dizer sobre o direito de possuir a terra é um judeu ortodoxo, que apresenta o argumento sionista fundamentado na Torah:

quando um árabe me vê, ele pensa que fui eu que tomei a terra dele. Eles acham que a terra é deles, e nós, que é nossa. Sabemos que é nossa. (...) Eu vou achar, não se preocupe [abre a Torah]. Porque Deus não deu esta terra a Israel e Abraão muitas vezes. Ele só deu uma vez. E por causa dessa única vez, esta terra é nossa. (Moishe Bar Am, citado em Promises, 2001)

No filme, a argumentação de Moishe está intercalada com os depoimentos de Mahmoud, Shlomo, Yarko, Sanabel e Faraj. Para esta discussão, pretende-se contrapor as palavras de ambos os meninos praticantes da religião tanto judaica quanto islâmica: Moishe e Mahmoud. O primeiro é o morador do assentamento judaico, Beit-El, localizado nas proximidades de Jerusalém. O segundo, Mahmoud, é filho de um comerciante árabe. O seu pai tem uma loja de café no bairro muçulmano da cidade antiga de Jerusalém. Na apresentação dele, o filme mostra a loja e Mahmoud trabalhando nela, em seguida é possível localizar a loja numa rua estreita e bastante movimentada. Ele sai da loja, após carregar um carrinho de pacotes de café pelas ruas do bairro. A câmera filma: alguns soldados israelenses; muros pintados com algumas figuras, cujas cores representam a bandeira da Palestina; homens e mulheres usando as vestimentas tradicionais dos árabes; e finaliza na imagem de uma edificação cristã.

Os judeus dizem que essa terra é deles. Como a terra pode ser deles? Se a terra é deles, por que o Alcorão diz que Maomé fugiu de Meca para a Mesquita Al-Aqsa em Jerusalém? Então, Jerusalém é nossa! Dos árabes! (...) Não é de Israel, é dos árabes. É nossa. Essa terra é minha! Nasci e fui criado aqui. Você não tem o direito de tomar a terra. (Mahmoud Mazen Mahmoud Izhman, citado em Promises, 2001)

Este contundente problema, expresso nas palavras de Mahmoud, orienta as ações das pessoas que vivem nesta sociedade segregada. Em Jerusalém, a arquitetura da cidade evoca a fé dos três "grandes monoteísmos", a saber: Judaísmo, Cristianismo e Islamismo (Armstrong, 2001. p. 9). Moishe e Mahmoud não têm dúvidas sobre os seus direitos de pertencimento nesta terra, Moishe conhece as escrituras judaicas, assim como Mahmoud também é educado nos princípios da fé islâmica. O documentário exibe uma cena em que Mahmoud 
está em uma aula da escola islâmica para meninos, em Jerusalém. A discussão da aula é sobre a liberdade em vista da situação dos palestinos naquela localidade. O professor faz algumas perguntas aos meninos, entre elas: "vocês gostam de liberdade? As crianças da Palestina vivem em liberdade?" (Promises, 2001). Ele continua o seu raciocínio dizendo que muitos muçulmanos não podem ir a Jerusalém rezar e por isso são privados de sua liberdade. Mahmoud vai para o quadro e faz um desenho que representa a revolta dos palestinos. Mahmoud desenha uma criança com uma pedra na mão e outra chorando porque perdeu a sua mãe. A reação das crianças é quase sempre identificada com a pedra.

A história da promessa de Deus a Abraão lida por Moishe fundamenta a crença judaica na qual o sionismo atribui significado. Os judeus, a partir desta proposição, possuem um elo com a terra desde a antiguidade. Para os árabes, Jerusalém adquiriu o status de sacralidade no século VII a partir do advento do islamismo. Neste período ocorreu, conforme Hitti,

a dramática viagem noturna em que o Profeta, segundo se diz, foi transportado instantaneamente da Caaba a Jerusalém, como preparação à sua ascensão ao sétimo céu. Por ter servido assim como estação terrestre nesta viagem memorável, Jerusalém, já sagrada para os judeus e cristãos, tornou-se e tem continuado a ser, depois de Meca e Medina, a terceira das cidades mais sagradas para o mundo muçulmano. (Hitti, 1948, pp. 29-30).

Mahmoud não cita o sonho do Profeta Maomé, mas ressalta a importância de Jerusalém para os muçulmanos. Para além da religiosidade destes povos - representada nas vozes destas crianças e que, no limite, orienta a luta de judeus e árabes - o filme, pelo viés dos seculares, também articula opinião. Yarko, judeu secular, a respeito de sua cidade vai dizer: "os palestinos estão abusando! Querem Jerusalém para a sua capital. Podem esperar sentados!". Para ele, Israel tem o direito sobre a terra por ter vencido a guerra de 1948.

\section{O PROCESSO de PAZ}

Tenho provas de que esta terra é nossa, e tenho o direito de construir nela! Então, vamos ter paz. Não vamos fazer mal para os judeus nem eles para a gente. Tenho o direito de voltar pra vila. (...) Quero voltar para Ras Abu Ammar! Se não for na minha geração, quem sabe, na próxima. Um dia, vamos libertar a Palestina e voltar para Ras Abu Ammar.(Faraj Adnan Hassan Hussein, citado em Promises, 2001).

Os judeus ainda estão na nossa terra, não deixaram nenhum espaço. (...) Eles pegam as pessoas e põem elas na prisão. Está errado. Para mim não há paz agora. (Sanabel Hassan Abd'el Jawad, citado em Promises, 2001).

No final da década de 1970, após o acordo de Camp David (1979), acreditava-se que a via para a paz estava construída e que os israelenses e os árabes enfim poderiam 
avançar nas negociações sobre o futuro da Palestina. Contudo, inúmeros acontecimentos seguiram frustrando as propostas de paz, entre eles: a invasão israelense no sul do Líbano que teve como objetivo destruir a força militar da Organização para a Libertação da Palestina (OLP), em 1982, e o levante palestino que ocorreu em dezembro de 1987 - na Cisjordânia e na Faixa de Gaza - conhecido como intifada. Segundo Morris (2014), o desencadeamento destes dois eventos propiciou a Declaração de Independência Palestina, escrita pelo poeta palestino Mahmoud Darwish e traduzida para o inglês pelo intelectual palestino norte-americano, Edward Said. Este documento palestino aponta a intifada como um "impulso revolucionário irreversível" 6 para a história deste povo árabe, que outrora militava pela libertação dos palestinos e neste momento passa a enfatizar o discurso da independência nacional.

Em meio à intifada, após algumas negociações entre o governo israelense e a OLP, no dia 11 de fevereiro de 1993 - na cidade de Oslo, Noruega - a liderança árabe palestina aceitou a proposta inicial para o estabelecimento do acordo de paz. O presidente Bill Clinton, no início do seu mandato, foi informado do compromisso firmado em Oslo, através da visita de Shimon Peres aos Estados Unidos a pedido do primeiro ministro de Israel, Yitzhak Rabin. Para a efetivação do acordo foi necessário o reconhecimento mútuo entre as autoridades representantes, ou seja, Israel deveria aceitar a liderança da OLP como representante da causa Palestina e a OLP precisaria reconhecer a existência do Estado de Israel.

No acordo, Israel deveria retirar suas forças militares - deixando o controle dos territórios adquiridos em 1967 - e interromper os assentamentos, reconhecendo assim, a autoridade palestina. Os palestinos, além de reconhecer o direito à existência do Estado de Israel, deveriam renunciar ao terrorismo praticado durante o período de guerra. As diretrizes para o cumprimento do acordo salientavam que a aplicação deveria ocorrer de forma gradual e as duas partes teriam que se empenhar para isto.

O acordo de Oslo marcou o início do processo de paz e o fim da intifada (19871993). Neste período, 1993 até setembro de 2000, o território delimitado pelo rio Jordão e o mar Mediterrâneo contou com uma experiência de relativa paz. É provável inferir que isto se deu como consequência do acordo firmado em Oslo e assinado na Casa Branca, considerando que os termos do acordo foram respeitados e observados; todavia, a história apresenta outra direção para esta problemática.

Faraj nasceu no Campo de Refugiados, em Deheishe. Ele não se identifica com esta localidade. O lugar que ele escolheu para pertencer é Ras Abu Ammar, uma antiga aldeia ocupada pelos israelenses, onde morava a sua família antes da ocupação. Tanto Faraj como Sanabel evidenciam o descontentamento por permanecer em Deheishe. Moishe, Mahmoud, Shlomo, Yarko, Sanabel e Faraj discorrem sobre a ocupação que ocasionou a perda dos direitos palestinos sobre a terra. Há nesta discussão dois momentos em que a palavra paz aparece. O primeiro está na fala de Sanabel e o segundo quando Faraj argumenta sobre a questão. As outras crianças não mencionam a paz, apesar de compreenderem as tensões pertinentes a este debate. É possível inferir que a produção

${ }^{6}$ Declaração de Independência Palestina. Retirado de http://vivapalestina.com.br/ declaracao-de-independencia-palestina-15-de-novembro-de-1988/ 
precisou este debate para centralizá-lo no filme apontando a questão da terra como o ponto crucial para a compreensão do conflito. Nos quarenta minutos do filme - após a finalização das cenas que reportam sobre o pai de Sanabel na prisão e a bela imagem ao entardecer que expõe a cúpula dourada do Domo da Rocha -, Promises traz os depoimentos das crianças aqui apresentadas e, em meio a esta discussão, deixa para o observador a lacuna sobre o que está em pauta.

Há duas questões que aparecem de forma subjetiva e que podem ser consideradas do ponto de vista daquilo que a produção deste documentário poderia alcançar. $A$ primeira é a problemática da terra, a segunda diz respeito às disputas entre árabes $\mathrm{e}$ judeus, tendo como premissa a questão da etnicidade. Ambos disputam o direito de possuir a terra e fundamenta este direito tanto pelo viés da religiosidade quanto pelo histórico da ocupação neste espaço geográfico. Afinal, a terra pertence a quem por direito, aos árabes ou aos judeus? Haverá êxito no processo de paz sem que este problema seja solucionado? Além de Goldberg - que tinha memórias da sua infância -, Shapiro e Bolado não possuíam a experiência daquelas crianças quanto ao vivido. Todavia, os três diretores conheciam as deliberações políticas sobre o recente acordo que naquele momento vigorava e os desdobramentos advindos dele, uma vez que foi muito difundido pela imprensa mundial. Um fato relevante e que está ausente no filme é o atentado ao primeiro ministro de Israel, Yitzhak Rabin, como forma de protesto pelo encaminhamento das negociações aqui mencionadas.

Logo após Oslo, houve inúmeros indícios de forças opositoras israelenses e palestinas revoltosas com o processo de paz. Em fevereiro de 1994, Baruch Goldstein, um judeu fundamentalista, matou 29 árabes palestinos na Mesquita Ibrahimiyya, em Hebron. Em abril, um membro do Hamas matou seis israelenses em Afula, explodindo-se com uma bomba. Apesar do descontentamento de palestinos e israelenses e, por conseguinte, algumas ações que visavam minar o processo de paz, Rabin permaneceu com a política de buscar a solução para o conflito. Conforme Cohn-Sherbok, "Rabin avisou que esses atos terroristas não impediriam o governo israelense de buscar um acordo com a OLP" (Cohn-Sherbok \& El-Alami, 2005, p. 96). No dia 4 de julho de 1995, o governo de Israel, representado por Shimon Peres, com vista a continuar as negociações, reuniu-se com Arafat para os ajustes de Oslo II. Este acordo tratava especificamente do controle palestino na Margem Ocidental, implicando assim, a retirada das forças israelenses. Em setembro do mesmo ano, Rabin assinou Oslo II.

O primeiro ministro de Israel foi acusado pelos opositores de trair o seu país. Houve manifestações em Jerusalém desta ala considerada de direita em que apontavam o acordo como uma "traição à terra bíblica de Israel" (Cohn-Sherbok \& El-Alami, 2005, p. 98). Passado alguns dias, depois de ser acusado de traidor do Estado judaico - após um comício em apoio ao processo de paz que aconteceu em Tel-Aviv - Yitzhak Rabin foi assassinado por Yigal Amir, judeu ortodoxo e estudante da Universidade Bar-IIlan. Devido a este fatídico episódio e a continuidade do terrorismo palestino, o partido de direita Likud conseguiu eleger Benjamin Netanyahu, como primeiro ministro de Israel, ocasionando assim, entre 1996 a 1999, uma paralisia no processo de paz. 
O governo de Netanyahu, "rejeitou o legado de Rabin" (Cohn-Sherbok \& El-Alami, 2005, p.195) e abalou a esperança da criação de um Estado palestino independente. O processo de paz que já estava fragilizado pelos diversos acontecimentos, foi arrefecido ainda mais. Houve expansão das colônias judaicas, sendo que o ano de 1997 foi marcado pelo aumento do número de assentamentos judaicos na Margem Ocidental. Além disso, Netanyahu apoiou o projeto arqueológico que tratava da abertura de um túnel em Jerusalém, o qual passava pelas fundações da Mesquita al-Aqsa.

Com vista nestes desdobramentos, o presidente Bill Clinton convidou as autoridades da OLP e de Israel para um acordo efetivo, após a Conferência Wye River7, em Maryland. Além de Arafat e Netanyahu, o Rei Hussein, da Jordânia, participou como mediador das negociações que aconteceram na Casa Branca, em 1998. Apesar das intervenções aqui mencionadas, não houve avanço significativo. No ano seguinte, Ehud Barak, do Partido Trabalhista, venceu as eleições e novas negociações foram realizadas dando indícios de que o processo de paz seria priorizado. Desta vez, em outra localidade, contando com a presença do governo do Egito e da Jordânia - implementando o acordo de Wye River - Barak e Arafat assinaram no dia 5 de setembro de 1999 o acordo Sharm al-Shaykh. Ficou acordado sobre a retirada israelense da Margem Ocidental por fases; libertação de prisioneiros palestinos; construção do Porto de Gaza e estradas de desvio; segurança de Israel e a economia de ambas as partes.

Depois da guerra de 1967, grupos de nacionalistas judeus estabeleceram assentamentos aqui onde previamente era terra árabe. Terra que crêem ser a região bíblica da Judéia e Samaria. O governo de Israel apoiou a ocupação dos territórios e, hoje, há mais de 150 mil assentamentos na Cisjordânia. Beit-El é um dos maiores e mais antigos assentamentos. Como todos os assentamentos, Beit-El tem proteção militar constante. (Goldberg citado em Promises, 2001)

A região referenciada por Goldberg era uma questão basilar das negociações que levaram ao acordo iniciado em Wye River e que foi concluído na cidade de Sharm al-Shaykh, na Península de Sinai. Segundo El-Alami, "a retirada israelense da área palestina aconteceria em três estágios (de setembro de 1999 a janeiro de 2000). Também houve promessa verbal de retirada de áreas ainda a serem designadas" (Cohn-Sherbok \& El-Alami, 2005, p. 197).

Moishe reside em Beit-El, a vinte minutos de Jerusalém; segundo ele, o lugar é cercado por árabes. Moishe é um judeu religioso. Ele discursa sobre a ocupação e a presença árabe ao derredor do assentamento com a particularidade de quem conhece o porquê de residir ali. Durante os depoimentos, Moishe demarca com clareza qual é o lugar do outro: "aqui moram as pessoas que lutam contra os árabes (...) esta cerca aqui nos separa daquela aldeia árabe ali”. Estas frases elucidam que o assentamento não

\footnotetext{
${ }^{7}$ Conforme Cohn-Sherbok e El-Alami (2005), a Conferência de Wye River, em Marylan, foi promovida pelo presidente norte-americano Bill Clinton para os israelenses e palestinos tentarem "alcançar um acordo" (p. 96). As negociações duraram nove dias.
} 
é uma divisão apenas territorial, mas principalmente um entrave nas relações desses povos. Moishe ainda declara: "quero que Barak faça uma coalizão com o partido pró-assentamentos. la ser a combinação perfeita, mas não ia funcionar nunca" (Moishe citado em Promises, 2001). A paz para ele não estava fora das proposições aceitáveis, todavia, desocupar o assentamento no qual provavelmente viveu desde o seu nascimento, não seria palatável.

\section{SionisMo E RESISTÊNCIA PALESTINA}

Refugiados, não se preocupem! Vamos sacrificar o nosso sangue! Negociadores não se vendam! De Deheishe a Bagdá! Uma frente indestrutível! Não haverá a paz até findar o colonialismo! Dizemos isso abertamente. Não queremos ver sionistas! Filhos da Pedra! Isto não é paz! Que a bandeira tremule no alto! (Promises, 2001)

$\mathrm{Na}$ mão de um árabe idoso uma chave é erguida. Em meio a algumas crianças e muitos fotógrafos, logo a cena revela que este homem está acompanhado com mais dois árabes do mesmo aspecto, dois com as chaves nas mãos e os três usando o tradicional Guthra ${ }^{8}$. Homens, mulheres e crianças marcham pelas ruas de Deheishe. Os gritos de guerra destacados acima fazem parte desta manifestação que aconteceu neste Campo de Refugiados. É evidente, a partir destas palavras, que a OLP representada por Yasser Arafat estava dividida. Possivelmente esta manifestação foi articulada pela FPLP, uma vez que o pai de Sanabel, em Deheishe, era líder local desta frente de oposição à ocupação israelense. Eles se posicionaram contrários ao acordo que deu início às negociações, negando a paz que poderia ser atingida por esta via. O que está elucidado a partir deste excerto é que estes palestinos ansiavam pelo fim do colonialismo judaico e o afastamento dos sionistas das terras em disputa.

Colonialismo e sionismo são termos que se imbricam quanto a sua compreensão na questão palestina. Segundo Said, o sionismo para os judeus é benéfico, pois os salvou do abandono e do antissemitismo - além de restabelecer a sua nacionalidade - porém, tornou-se para os árabes o agente de uma cultura "essencialmente forte e discriminatória" (Said, 2012, p. 81). Para mais, é válido salientar que os judeus sefarditas, oriundos na maioria de países árabes e muçulmanos, não puderam se beneficiar da mesma forma que os asquenazes, judeus ocidentais. Shohat afirma que o sionismo, embora

alegue oferecer uma pátria a todos os judeus, essa pátria não está aberta a todos com a mesma largueza. Os judeus sefarditas foram levados pela primeira vez a Israel por motivos sionista-europeus específicos, e, desde que chegaram lá, foram sistematicamente discriminados por um sionismo que destinava desigualmente esforços e recursos materiais, sempre favorecendo os judeus europeus e preterindo os orientais. (Shohat, 2007, p. 118)

${ }^{8} \mathrm{O}$ lenço que os homens árabes usam na cabeça. Há diferenças na tradição desta vestimenta dependendo de cada localidade. Retirado de http://www.destinodubai.com.br/2015/08/19/entenda-a-roupa-usada-pelos-homens-arabes/ 
O colonialismo judaico não é um movimento que representa os povos orientais e muito menos se fundamenta em ideias oriundas do Oriente, mas está baseado em princípios europeus fortemente desenvolvidos no século XIX e XX. Alguns países europeus, no século XIX, dominaram política e economicamente grande parte do globo e deixaram o modelo como legado para outros que despontaram no seguinte século: "a história do século XX do mundo não ocidental (...) é portanto determinada por suas relações com os países que se estabeleceram no século XIX como os senhores da espécie humana" (Hobsbawm, 1995, p. 199).

O sionismo, logo, antes de se concretizar como Estado de Israel foi uma prática cuja raiz está no colonialismo europeu. É válido ressaltar que este sionismo é caracterizado por articulações políticas e não religiosas, ou seja, apesar de ter sido justificado através de um preceito religioso que sustenta que Sião é a terra prometida por Deus ao povo judeu, a mobilização do movimento sionista se deu pelo viés político e apropriou-se de uma prática europeia comum naquele período. Said se propôs a criticar o sionismo não pelo que ele representou aos judeus, vítimas do antissemitismo, mas por aquilo que ocasionou para os árabes nativos da Palestina. Antes de considerar um movimento libertador para os judeus, já havia se tornado opressivo porque estava engendrado nas práticas de dominação do Ocidente. Said ainda salienta: "o imperialismo era a teoria, o colonialismo era a prática de transformar os territórios vagos e sem utilidade do mundo em versões úteis da sociedade metropolitana europeia" (Said, 2012, p. 88).

\section{AS PROMESSAS DO DOCUMENTÁRIO}

As quatro crianças israelenses escolhidas para as entrevistas e depoimentos, excluindo as participações secundárias, são: Yarko, Daniel, Moishe e Shlomo. Neste viés de análise, os dois primeiros ganham destaque no filme. São judeus seculares e apegados a outros estímulos que não a religião. Faraj e Sanabel, da mesma forma, são os participantes em destaque do lado árabe palestino. Yarko, Daniel e Faraj são esportistas e Sanabel dançarina. O esporte e a dança são instrumentalizados pela produção para promover um encontro entre eles. Como Faraj e Sanabel residem no campo de refugiados, em Deheishe, eles não podem transitar pela cidade de Jerusalém. Diante deste fato, Goldberg propõe um encontro em Deheishe e para isto, quem deve se deslocar para lá é o Yarko e o seu irmão, Daniel.

O filme não revela o critério utilizado para a escolha das crianças que deveriam participar do encontro que marca o ápice desta produção. Também não informa se todos foram convidados. No filme, a proposta do encontro foi sugerida por Yarko, mas fica evidente que esta questão já estava em pauta. Depois de algumas cenas em que o assunto é debatido pelas crianças sobre esta possibilidade, Sanabel declara: "nenhuma criança palestina tentou explicar a nossa situação para os judeus. Árabes e judeus deviam se encontrar. Quero que as crianças se encontrem" (Promises, 2001). Faraj, após relutar, inverte a sua opinião e convida Yarko e Daniel para irem ao campo de Deheishe. O pai dos gêmeos diz que confia em Goldberg e em sua equipe, mas fica temeroso com o encontro. 
Shlomo é uma das crianças que não participa deste momento no filme. Goldberg o apresenta como filho de um ilustre rabino dos Estados Unidos. A câmera filma o bairro judeu em que Shlomo nasceu, em Jerusalém, e o pai o levando para as orações no Muro das Lamentações. O filme exibe a rotina deste menino, judeu ortodoxo, e informa que o seu período de estudo é de 12 horas por dia. Na prática de estudo é comum ficar balançando a cabeça, segundo Shlomo (citado em Promises, 2001): "ninguém diz para gente fazer isso enquanto estuda, mas diz no Gemara", que o povo de Israel, ao estudar a Torá, é como a chama de uma vela tremendo". Goldberg (citado em Promises, 2001) questiona o menino acerca da sua fé no judaísmo: "Shlomo quando você encontra um judeu como eu, não religioso, acha que é a sua missão aproximar-me do judaísmo?". Em inglês fluente, ele responde que alguns têm essa missão e outros não. Depende da orientação de Deus.

Em Deheishe, quando os israelenses chegam ao encontro, as crianças árabes já estão esperando para recepcioná-los. Em seguida dos cumprimentos, Faraj conversa com Yarko e narra alguns fatos sobre a intifada. Durante a sua explanação, os israelenses leem uma pichação: "a vitória é nossa. A sede da terra será saciada com sangue. Hamas". Quando entram na casa dos árabes as crianças comem, brincam de luta e se divertem. Neste encadeamento das cenas é possível identificar uma encenação-locação ${ }^{10}$. Independentemente das diferenças entre palestinos e israelenses, a cena comunica harmonia e comunhão: a refeição servida às crianças, o respeito para com os colegas e a alegria como o principal elemento. Na virada da cena, o cenário se altera para um ambiente externo, a marcante música de Abdel Gadir Salim, sugere um momento descontraído e com mais liberdade. Yarko tira a camisa para brincar de futebol. Esta ação pode significar que ele está se desarmando diante dos colegas. A brincadeira faz parte de uma convivência pacífica. Faraj se junta a ele, aparecendo na cena também sem camisa. $\mathrm{Na}$ sequência, as crianças brincam de estilingue, sendo que o objeto neste caso é evidenciado como um brinquedo e não utilitário da luta do povo palestino.

Quando retornam para o ambiente interno, o documentário aponta para um fechamento e nota-se que a sequência de imagens revela peculiaridades que vão além daquilo que possivelmente foi programado para a cena. O que se observa no desenrolar das cenas é que o encontro em Deheishe poderia significar o começo de uma amizade entre as crianças palestinas e israelenses, e isso representa o clímax de todo o filme. Contudo, a tomada da cena surpreende até mesmo Goldberg, que se comove com o depoimento de Faraj.

Hoje à tarde, comecei a pensar: o B. Z. vai embora logo (fala soluçando] E agora, ficamos amigos do Daniel e do Yarko. [B.Z Goldberg também chora] E eles vão esquecer nossa amizade, assim que o B.Z for embora. E todo

\footnotetext{
${ }_{9}$ Gemara foi escrita em aramaico e é uma coleção de "ensinamentos" sobre a tradição judaica. Retirado de http://www. vidapraticajudaica.com/single-post/2015/08/27/O-que-eh-Mishna-Gemara-Talmud-Midrash-PARTE-2

${ }^{10}$ Conforme Ramos (2008, p. 42), a encenação-locação é "feita em locação, no local onde o sujeito-da-câmera sustenta a tomada. O diretor, ou sujeito-da-câmera, pede explicitamente ao sujeito filmado que encene (...), que desenvolva ações com a finalidade prática de figurar para a câmera um ato previamente explicitado (...) distingue-se da encenação-construída pelo fato de a tomada ser realizada na circunstância de mundo onde o sujeito que é filmado vive a vida".
} 
o nosso esforço vai ser em vão. (Faraj Adnan Hassan Hussein, citado em Promises, 2001)

Ele desabafa neste momento porque conhecia a política de controle israelense e os limites impostos aos moradores do campo em Deheishe. Os campos de refugiados fazem parte do resultado da guerra de 1948, que ocasionou a fuga e expulsão de 750 mil palestinos. No caso de Deheishe, após 1967, Israel assumiu o controle, ocupando militarmente o campo que, na época do filme, contava com mais de 11 mil palestinos. Faraj sabia que as dificuldades da vida no campo seriam um impedimento para a continuidade da nova amizade com os israelenses de Jerusalém. É provável que neste momento, Goldberg, o tradutor que mediava o diálogo e o sujeito-da-câmera, tenham se deparado com uma realidade que iria para além dos seus esforços.

A produção fílmica, em vista disto, direciona a resolução do problema da convivência desses povos pela via do diálogo entre seculares. Isto, no limite, representa uma proposta de distanciamento das políticas do Estado frente às questões religiosas. Goldberg não é um judeu ortodoxo e nem mesmo um israelense, mas, como declarou Mahmoud, um judeu americano. A perspectiva do diretor já está comprometida com uma herança sócio-cultural estadunidense. Tendo como premissa que aquilo que se produz no mundo ocidental refere-se a uma perspectiva orientalista, há duas questões que podem ser suscitadas para explanar esta reflexão. A primeira diz respeito ao ideário ocidental que está calcado nos iluminismos"e a segunda sobre a representação que se faz da parcela do mundo que não cabe na primeira, ou seja, o Oriente.

$\mathrm{Na}$ análise de Said sobre esta dicotomia entre Ocidente e Oriente, percebe-se que não haveria este se aquele não o tivesse inventado. E mais, porque o Ocidente construiu "um rival cultural" procura autoafirmar-se depreciando a imagem do Outro. Para este autor, as representações sobre o Oriente despontaram no final do século XVIII e tinham como principal objetivo a dominação através da colonização. Em suas palavras, o Orientalismo surgiu "como um estilo ocidental para dominar, reestruturar e ter autoridade sobre o Oriente" (Said, 2007, p. 29).

Uma das vertentes dos iluminismos é o afastamento das proposições fincadas em princípios religiosos e esta ideia parte da centralização do Homem como único agente capaz de solucionar problemas. A inauguração, portanto, do secularismo tem raízes neste período e passou a orientar, nos séculos vindouros, as práticas do mundo ocidental.

Shohat e Robert (2006) problematizam as representações cinematográficas do Ocidente, considerando as imbricações das políticas neocoloniais do século XX e expondo figuras e estereótipos deste representado. A questão central é o eurocentrismo, "uma perspectiva paradigmática que vê a Europa como a origem única dos significados, como o centro da gravidade do mundo" (p.20), que estabelece o lugar do Outro como aquele que pode estar próximo ou distante, arbitrando a partir da sua ótica. Os autores salientam ainda:

\footnotetext{
"Segundo Israel, havia diferentes propostas iluministas no final do século XVIII, entre elas, o autor destaca: "Iluminismo democrático Radical e o lluminismo antidemocrático moderado". O primeiro calcado na razão, e o segundo, na razão e na tradição (Israel, 2013, p. 21).
} 
o eurocentrismo purifica a história ocidental ao passo que trata com condescendência, ou mesmo com horror, o não-ocidental. Ele pensa sobre si mesmo com base em suas conquistas mais nobres - a ciência, o progresso, o humanismo - e sobre o não-ocidental com base em suas deficiências, reais ou imaginárias. (Shohat \& Robert, 2006, p. 20)

Promises não se apartaria desta herança cultural. A questão não é qualificar o filme como uma representação depreciativa dos povos da Palestina, mas de procurar compreender a sua proposta dentro da perspectiva tanto do contexto histórico quanto do lugar de produção, como documentário estadunidense.

\section{CONSIDERAÇÕES FINAIS}

O verão do ano 2000 marcou o fim da produção deste documentário. Na estação seguinte do mesmo ano uma nova intifada eclodiu na Palestina. O processo de paz foi um momento de abertura para o debate e até mesmo de flexibilizar as posturas de cada lado. Todavia, há apontamentos que revelam que o acordo trouxe terríveis consequências para o povo palestino, uma vez que não houve uma proposta de reparação da Nakba provocada pelo Estado de Israel desde 1948, através da política sionista de ocupação das terras palestinas. $O$ acordo visava restituir em partes os territórios ocupados a partir de 1967 e não reconhecia o direito de retorno para os refugiados palestinos. No final da década de 1990, devido às disputas políticas, o primeiro ministro de Israel, Ehud Barak, procurou retomar o acordo que ficou paralisado após o assassinato de Rabin. Conforme Pappé (2008), seria uma traição ao povo palestino - que lutava pela independência nacional - se a proposta para o acordo de Camp David no ano 2000 fosse aprovada. Arafat não assinou o acordo "e por isso os estadunidenses e israelenses o castigaram de imediato, apressando em apresentá-lo como um belicista". Esta humilhação, segundo Pappé, acrescida da visita provocadora de Ariel Sharon à Esplanada das Mesquitas, desencadeou a segunda Intifada (Pappé, 2008, pp. 318-319).

A década de 1990 marcou o tempo dos encontros. Em Moscou, Ottawa, Viena, Bruxelas e Washington os apertos de mão procuravam alguma forma de reconciliação. O encontro em Deheishe - encenado no filme - não tinha a representatividade das lideranças envolvidas no acordo, mas possuía um caráter singular, o agente era o futuro, representado pela figura da criança. O encontro de israelenses e palestinos, em Deheishe, simbolizou a promessa destes produtores que por sete anos se enveredaram no Oriente Médio na finalidade de retratar o conflito e articular opiniões sobre o mesmo.

A participação das crianças neste encontro desvela o projeto inicial da produção. Neste viés de análise, a convivência pacífica dos povos israelenses e palestinos dependeria do afastamento das posições mais radicais, sendo aqui representadas pelos adeptos das doutrinas religiosas de ambos os povos. No documentário, o encaminhamento das entrevistas e depoimentos - sem deixar de refletir sobre o encadeamento das cenas -, apontam para estes lapsos. As ações que orientam a política abusiva da ala radical árabe - fazendo do terrorismo uma prática constante -, e o insistente e permanente avanço 
dos assentamentos, podem ser enquadradas e vistas como reflexos de uma posição fundamentada nos preceitos religiosos destes povos.

Promises é uma voz que continua a reverberar pela paz no Oriente Médio. Nos últimos minutos do filme, após as crianças concederem os seus depoimentos - dois anos depois do encontro -, um pneu em chamas desce pela rua enquanto um soldado armado observa ao fundo algumas crianças que o confrontam com lançamentos de pedras. O conflito continua... Para finalizar, depois dos relatos desencorajadores das crianças, ao som da música "Darpa" (Mertens, 1991, faixa 1), o filme mostra o berçário de uma maternidade. Uma nova esperança. Os recém-nascidos, filhos de árabes e judeus, ainda não sabem sobre o mundo e sua gente, mas já estão sendo representados como agentes em potencial para a resolução de um conflito que tem mais de um século.

Esta última cena é emblemática visto que no início do documentário, em uma tela negra, a nova intifada é informada, colocando as promessas de paz no âmbito do irreconciliável, como se o documentário estivesse em luto pelas promessas não cumpridas. Sendo assim, o filme anuncia o que não foi possível no ano de 2001, mas permanece com a proposição de que o agente capaz de promover a paz é a nova geração de seculares, que continuarão esforçando-se para dialogar com o outro num futuro próximo. Segundo o filme, tanto israelenses quanto palestinos devem esforçar-se para um acordo de paz nos tempos vindouros, deixando as diferenças de lado, especialmente no que tange à religiosidade. $\mathrm{O}$ que o filme não aponta como causa determinante é que Israel é um Estado, e como tal, constituído de poder, e a Palestina ainda não pode dialogar como igual, porque não tem um espaço autônomo nesta geografia e nem mesmo poder político para isso.

\section{REFERÊNCIAS}

Armstrong, K. (2001). Em nome de Deus: o fundamentalismo no judaísmo, no cristianismo e no islamismo. SP: Companhia das Letras.

Burke, P. (2004). Testemunha ocular: história e imagem. Bauru, SP: EDUSC.

Cohn-Sherbok, D. \& El-Alami, D. (2005). O conflito Israel-Palestina: para começar a entender. SP: Palíndromo.

Goldberg, B. Z., Bolado, C. \& Shapiro, J. (Realizadores). (2001). Promises [Filme]. Estados Unidos da América: Promises Film Project.

Hitii, P. K. (1948). Os árabes. SP: Companhia Editora Nacional.

Hobsbawm, E. (1995). Era dos extremos: o breve século XX 1914-1991. SP: Companhia das Letras.

Israel, J. (2013). A revolução das Luzes: O Iluminismo Radical e as origens intelectuais da democracia moderna. SP: EDIPRO.

Mansurov, E. (1993). Bayaty [Gravada por Ashkhabad]. In Ashkhabad City of love [CD]. Alemanha.

Mertens, W. (1991). Darpa. In Strategie de la rupture [CD]. Bélgica.

Morris, B. (2014). Um Estado, dois Estados - soluções para o conflito Israel-Palestina. SP: Ed.Sêfer. 
Nichols, B. (2005). Introdução ao documentário. Campinas, SP: Papirus

Pappé, I. (2008). La limpieza étnica de Palestina. Barcelona: Crítica Barcelona.

Poutignat, P., \& Streiff-Fenart, J. (1998). Teorias da etnicidade. Seguido de grupos étnicos e suas fronteiras de Fredrik Barth. SP: Fundação Editora da UNESP.

Ramos, F. P. (2008). Mas afinal... O que é mesmo documentário? SP: SENAC.

Said, E. (2007). Orientalismo: o Oriente como invenção do Ocidente. SP: Companhia do Bolso.

Said, E. (2012). A questão da Palestina. SP: Unesp.

Shohat, E. \& Robert, S. (2006). Crítica da imagem eurocêntrica. SP: Cosas Naify.

Shohat, E. (2007). Os Sefarditas em Israel - O sionismo do ponto de vista das vítimas judaicas. Novos Estudos, 79, 117-136. Retirado de http://www.scielo.br/pdf/nec/n79/o6.pdf

\section{NOTA BIOGRÁFICA}

Claudinei Lodos é mestrando do curso de pós-graduação em História da Universidade Federal de São Paulo, Brasil. Desenvolve pesquisa sobre a questão Palestina, com ênfase em análise fílmica. Participou no V COCAAL (Colóquio de Cinema e Arte da América Latina), em 2017, e da ANPUH - SP (Associação Nacional de História), em 2018, com a comunicação intitulada "A questão da identidade no documentário Nosotros, Ellos y Yo (2015), de Nicolás Avruj". Participa do Laboratório de Estudos Orientais e Asiáticos (LEOA), da Unifesp. Em novembro de 2018, colaborou na organização do I Encontro do LEOA intitulado "Oriente Médio: histórias, conflitos e identidades". Neste encontro, além de integrar a comissão de organização, participou como mediador da mesa: "Identidade judaica e Estado de Israel: debate do filme", cuja programação contou com a exibição do documentário NEY (2015) - objeto da pesquisa do curso de mestrado - e a presença do diretor Nicolás Avruj.

ORCID: https://orcid.org/0000-0001-5054-8304

Email: ney_lodos@hotmail.com

Morada: Universidade Federal de São Paulo - Unifesp, Rua Sena Madureira, n. ${ }^{\circ}$ 1.500 - Vila Clementino - São Paulo - SP - CEP: 04021-001, Brasil

* Submetido: 10-09-2018

* Aceite: 01-02-2019 